Marquette University

e-Publications@Marquette

$1-1-2012$

\title{
A Synthetic Model of the Putative Fe(II)- Iminobenzosemiquinonate Intermediate in the Catalytic Cycle of o-Aminophenol Dioxygenases
}

Michael M. Bittner

Marquette University, michael.bittner@marquette.edu

Sergey V. Lindeman

Marquette University, sergey.lindeman@marquette.edu

Adam T. Fiedler

Marquette University, adam.fiedler@marquette.edu

Accepted version. Journal of the American Chemical Society, Vol. 134, No. 12 (2012): 5460-5463.

DOI. (C) 2012 American Chemical Society. Used with permission. 


\title{
A Synthetic Model of the Putative Fe(II)-Iminobenzosemiquinonate Intermediate in the Catalytic Cycle of $o$-Aminophenol Dioxygenases
}

\author{
Michael M. Bittner \\ Department of Chemistry, Marquette University, \\ Milwaukee, WI \\ Sergey V. Lindeman \\ Department of Chemistry, Marquette University, \\ Milwaukee, WI \\ Adam T. Fiedler \\ Department of Chemistry, Marquette University, \\ Milwaukee, WI
}




\section{Abstract}

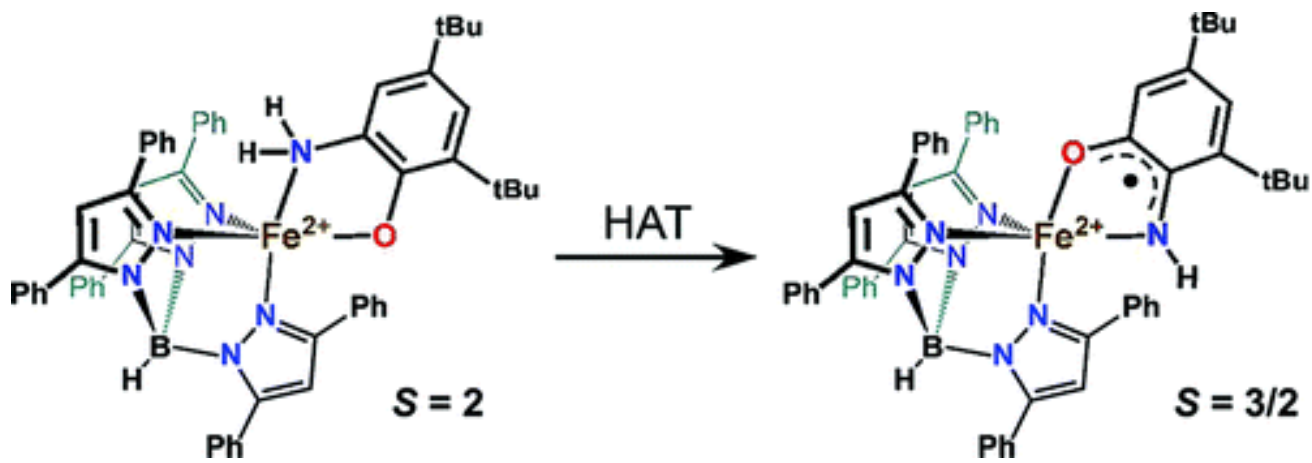

The oxidative ring cleavage of aromatic substrates by nonheme Fe dioxygenases is thought to involve formation of a ferrous-(substrate radical) intermediate. Here we describe the synthesis of the trigonal-bipyramdial complex $\mathrm{Fe}\left({ }^{\mathrm{Ph} 2} \mathrm{Tp}\right)\left(\mathrm{ISQ}^{\mathrm{tBu}}\right)(\mathbf{2})$, the first synthetic example of an iron(II) center bound to an iminobenzosemiquinonate (ISQ) radical. The unique electronic structure of this $S=3 / 2$ complex and its one-electron oxidized derivative $\left([3]^{+}\right)$have been established on the basis of crystallographic, spectroscopic, and computational analyses. These findings further demonstrate the viability of $\mathrm{Fe}^{2+}$-ISQ intermediates in the catalytic cycles of 0 -aminophenol dioxygenases.

In biochemical pathways, the oxidative ring cleavage of substituted aromatic compounds, such as catechols and $o_{-}$ aminophenols, is generally performed by mononuclear nonheme iron dioxygenases. ${ }^{1}$ While these enzymes are usually found in bacteria, some play important roles in human metabolism: for instance, a key step in tryptophan degradation involves the $\mathrm{O}_{2}$-mediated ring cleavage of 3-hydroxyanthranilate (HAA) by HAA-3,4-dioxygenase (HAD; Scheme 1). ${ }^{2}$ With the exception of the intradiol catechol dioxygenases, the ring-cleaving dioxygenases share a common $\mathrm{O}_{2}$-activation mechanism, illustrated in Scheme 2. ${ }^{1}$ A notable feature of this proposed mechanism is the superoxo- $\mathrm{Fe}^{2+}$-(iminobenzo)semiquinonate intermediate (B) that is thought to form after $\mathrm{O}_{2}$ binding to the enzyme-substrate complex (A). The development of radical character on the substrate ligand presumably facilitates reaction with the bound superoxide, yielding the key $\mathrm{Fe}^{2+}$-alkylperoxo intermediate $(\mathbf{C}) .^{3}$ Although the electronic structure of $\mathbf{B}$ remains somewhat controversial, ${ }^{4}$ evidence in favor of substrate radical character has been provided by radical-trap experiments ${ }^{5}$ and DFT calculations, ${ }^{3}$ as well as a remarkable $\mathrm{X}$-ray structure of the $\mathrm{Fe} / \mathrm{O}_{2}$ adduct of an 
extradiol dioxygenase in which the radical character of the bound substrate was inferred from its nonplanar geometry. ${ }^{6}$

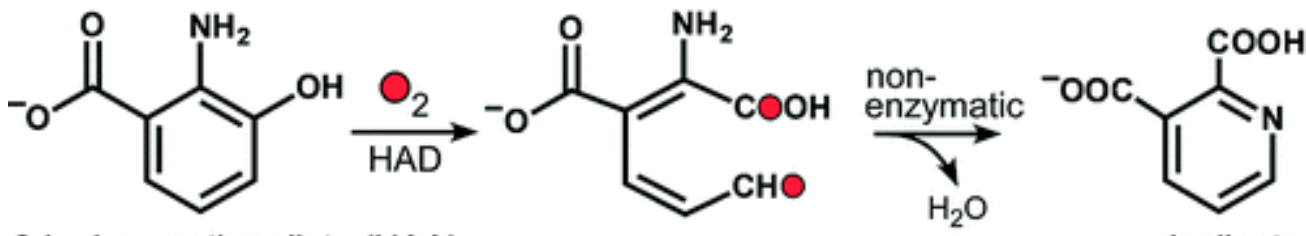

3-hydroxyanthranilate (HAA)

quinolinate

Scheme 1. Reaction Catalyzed by HAA Dioxygenase (HAD)

Despite these biological precedents, synthetic analogues of intermediate $\mathbf{B}$ in which a ferrous center is coordinated to an (iminobenzo)semiquinone radical, (I)SQ, have been lacking in the literature, even though numerous ferric complexes with such ligands exist. ${ }^{7-11}$ Herein, we report the synthesis and detailed characterization of an $\mathrm{Fe}^{2+}$-ISQ complex, 2, that represents the first synthetic model of this important type of enzyme intermediate. We also examine the geometric and electronic structures of the species $[\mathbf{3}]^{+}$generated via one-electron oxidation of $\mathbf{2}$.

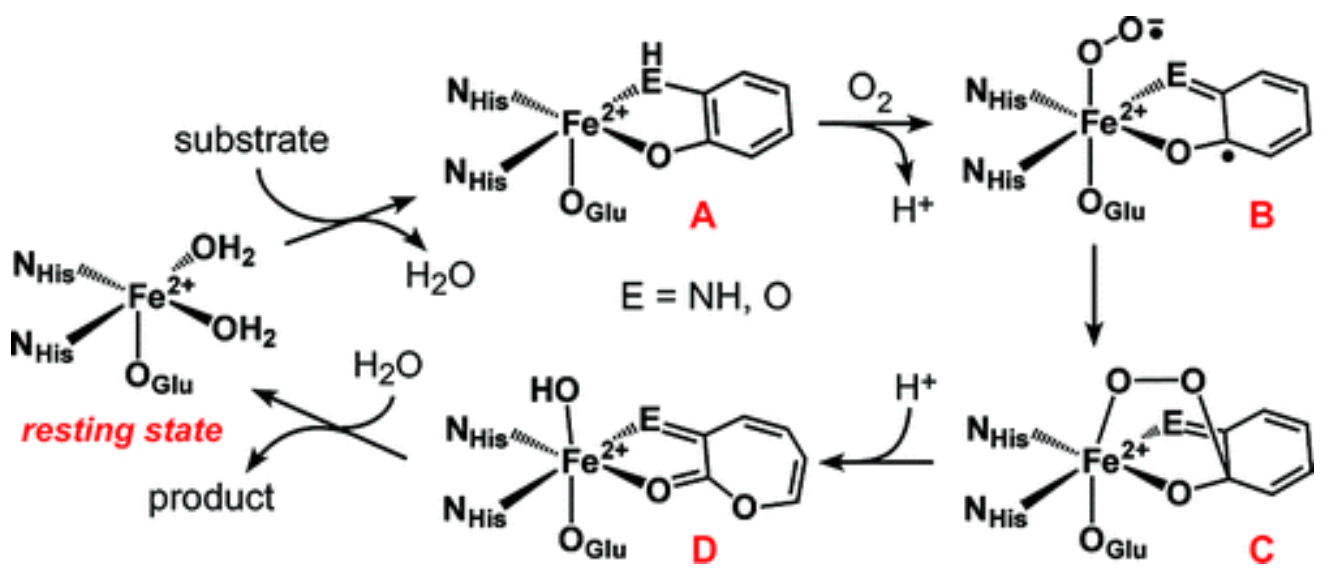

Scheme 2. Catalytic Cycle of Ring-Cleaving Dioxygenases

In our efforts to generate synthetic models of HAD, we have used the tris(pyrazolyl)borate ligand, ${ }^{\mathrm{Ph}} 2 \mathrm{Tp},{ }^{12}$ to mimic the facial $\mathrm{His}_{2} \mathrm{Glu}$ coordination environment of the enzyme active site. The reaction of $\left[\left({ }^{\mathrm{Ph} 2} \mathrm{Tp}\right) \mathrm{Fe}(\mathrm{OBz})\right]^{13}$ with 2-amino-4,6-di-tert-butylphenol $\left({ }^{\mathrm{tBu}} \mathrm{APH}_{2}\right)$ in the presence of base provided the light yellow complex $\left[\left({ }^{\mathrm{Ph} 2} \mathrm{Tp}\right) \mathrm{Fe}^{2+}\left({ }^{\mathrm{tBu}} \mathrm{APH}\right)\right](\mathbf{1})$ in $71 \%$ yield. The $\mathrm{X}$-ray crystal structure of $\mathbf{1}$ reveals a five-coordinate $(5 \mathrm{C}) \mathrm{Fe}^{2+}$ center in which the ${ }^{\mathrm{tBu}} \mathrm{APH}^{-}$ligand binds in a bidentate fashion (Figure 1; crystallographic details are 
summarized in Table S1 in the Supporting Information). The average Fe1- $\mathrm{N}_{\mathrm{Tp}}$ bond length of $2.15 \AA$ is typical of high-spin $\mathrm{Fe}^{2+}$ complexes with Tp ligands, ${ }^{13,14}$ while the short Fe1-O1 distance of 1.931 (1) $\AA$ is consistent with coordination by an aminophenolate anion (Table 1 ). The complex adopts a distorted trigonal-bipyramidal geometry ( $\mathrm{T}=$ $0.61^{15}$ ) with the amino group of ${ }^{\mathrm{Bu}} \mathrm{APH}^{-}$in an axial position trans to N5. To the best of our knowledge, $\mathbf{1}$ represents the first synthetic model of an aminophenol dioxygenase.

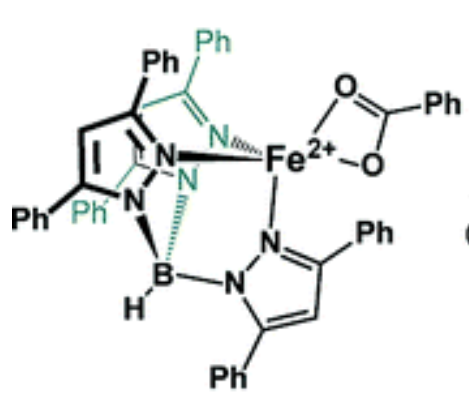
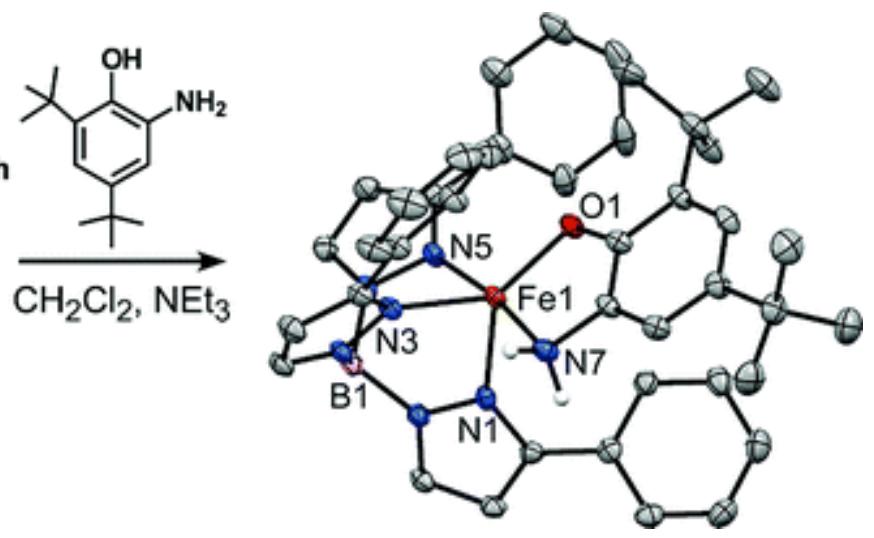

Figure 1. Synthesis and thermal ellipsoid diagram of complex 1. For the sake of simplicity, the 5-Ph substituents of the ${ }^{\mathrm{Ph} 2} \mathrm{Tp}$ ligand have been omitted and only the amino hydrogens are shown. Selected bond lengths are provided in Table 1.

Reaction of 1 with 1 equiv of 2,4,6-tri-tert-butylphenoxy radical (TTBP•) at RT in $\mathrm{CH}_{2} \mathrm{Cl}_{2}$ gives rise to a distinct chromophore, $\mathbf{2}$, with a broad absorption manifold centered at $715 \mathrm{~nm}\left(\varepsilon_{\max }=0.76 \mathrm{mM}^{-1} \mathrm{~cm}^{-}\right.$ 1 ; see Figure 2). Addition of $\mathrm{MeCN}$, followed by cooling to $-30{ }^{\circ} \mathrm{C}$, provides pale green crystals of $\mathbf{2}$ suitable for crystallographic analysis. As with $\mathbf{1}$, the X-ray structure of $\mathbf{2}$ features a neutral 5C Fe complex with a distorted trigonal-bipyramidal geometry $(T=0.58)$, although 01 now occupies an axial position instead of N7 (Figure S1). The N7 atom in $\mathbf{2}$ is monoprotonated, confirming that $\mathbf{2}$ is generated via abstraction of a $\mathrm{H}$-atom from the $-\mathrm{NH}_{2}$ group of $\mathbf{1}$. 


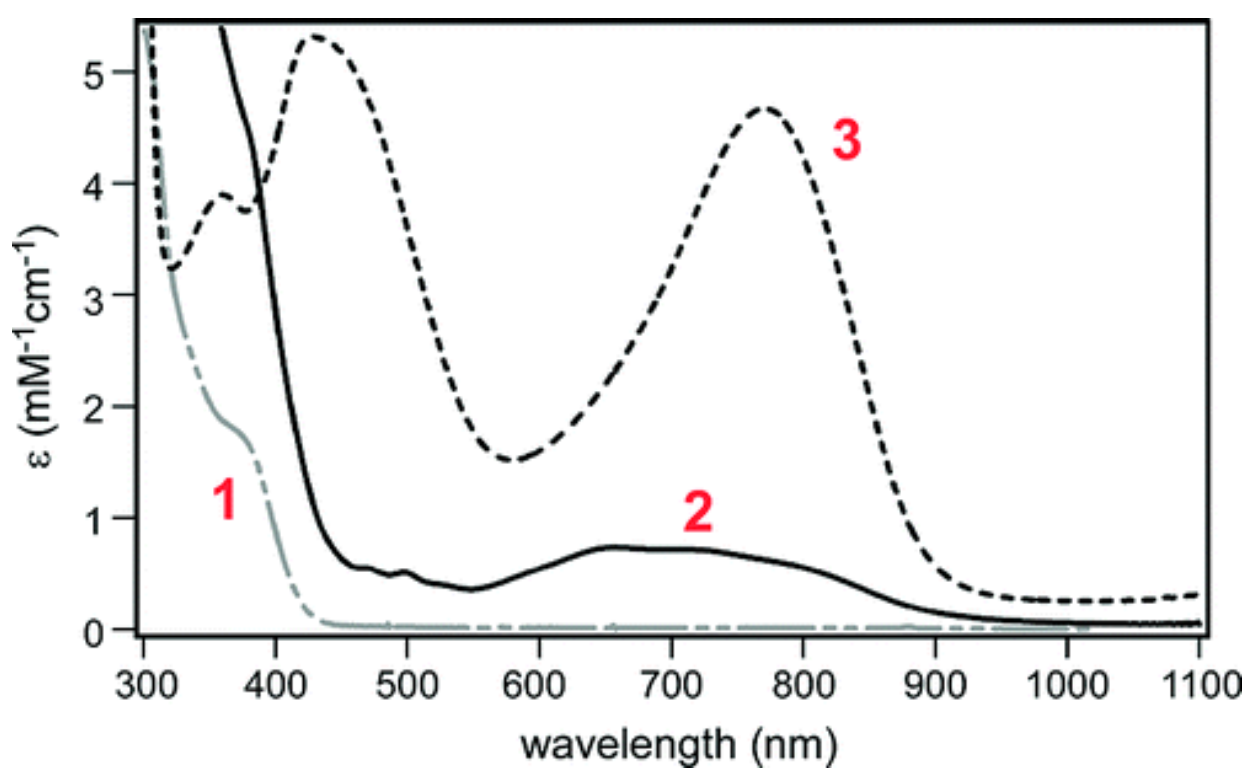

Figure 2. Electronic absorption spectra of $\mathbf{1}(---), \mathbf{2}(-)$, and [3]SbF $(---)$ measured in $\mathrm{CH}_{2} \mathrm{Cl}_{2}$ at RT.

Interestingly, the average Fe1- $\mathrm{N}_{\mathrm{Tp}}$ bond distance observed for $\mathbf{2}$ $(2.136 \AA)$ is nearly identical to the value found for $\mathbf{1}(2.150 \AA)$, suggesting minimal change in Fe charge. Metric parameters for the $\mathrm{O}, \mathrm{N}$-coordinated ligand, however, are dramatically different in the two structures. In the structure of $\mathbf{1}$, the six $\mathrm{C}-\mathrm{C}$ bonds of the ${ }^{\mathrm{tBu}} \mathrm{APH}^{-}$ring are approximately equidistant $(1.40 \pm 0.02 \AA)$, reflecting its closedshell, aromatic nature. In contrast, the corresponding $\mathrm{C}-\mathrm{C}$ bond distances in $\mathbf{2}$ exhibit the "four long/two short" distortion commonly observed for quinoid moieties (Table 1)..$^{7-11}$ The short O1-C1 and N7C2 distances of 1.285(3) and 1.328(4) $\AA$, respectively, are also characteristic of ISQ ${ }^{-}$ligands, as amply demonstrated by Wieghardt ${ }^{8-10}$ and others. ${ }^{7}$ Thus, the X-ray crystallographic data strongly support the formulation of $\mathbf{2}$ as [( $\left.\left.\left.{ }^{\mathrm{Ph} 2} \mathrm{Tp}\right) \mathrm{Fe}^{2+}{ }^{\mathrm{EB} u} \mathrm{ISQ}\right)\right]$. This assignment rationalizes the absorption spectrum of $\mathbf{2}$, which closely resembles those reported for $\mathrm{Co}^{3+}$ and $\mathrm{Ni}^{2+}$ complexes with a lone ISQ- ligand. ${ }^{9 a}$

The X-band EPR spectrum of $\mathbf{2}$ displays an intense peak at $g=$ 6.5 , along with a broad derivative-shaped feature centered near $g=$ 1.8 (Figure 3 ). Such spectra are typical of $S=3 / 2$ systems with large and rhombic zero-field splitting parameters. ${ }^{9,16}$ The simulated spectrum in Figure 3 assumed a negative $D$-value (with $|D| \gg h v$ ), an $E / D$-ratio of 0.24 , and $g$-values of $2.36,2.30$, and 2.17 . Significant $E / D$ strain was incorporated to adequately account for the broadness 
of the higher-field features. The combined experimental results therefore indicate that $\mathbf{2}$ contains a high-spin $\mathrm{Fe}^{2+}$ center $(S=2)$ antiferromagnetically coupled to a ${ }^{\mathrm{B} u} \mathrm{ISQ}$ radical anion.

Table 1. Selected Bond Distances $(\AA)$ for Complexes 1-3

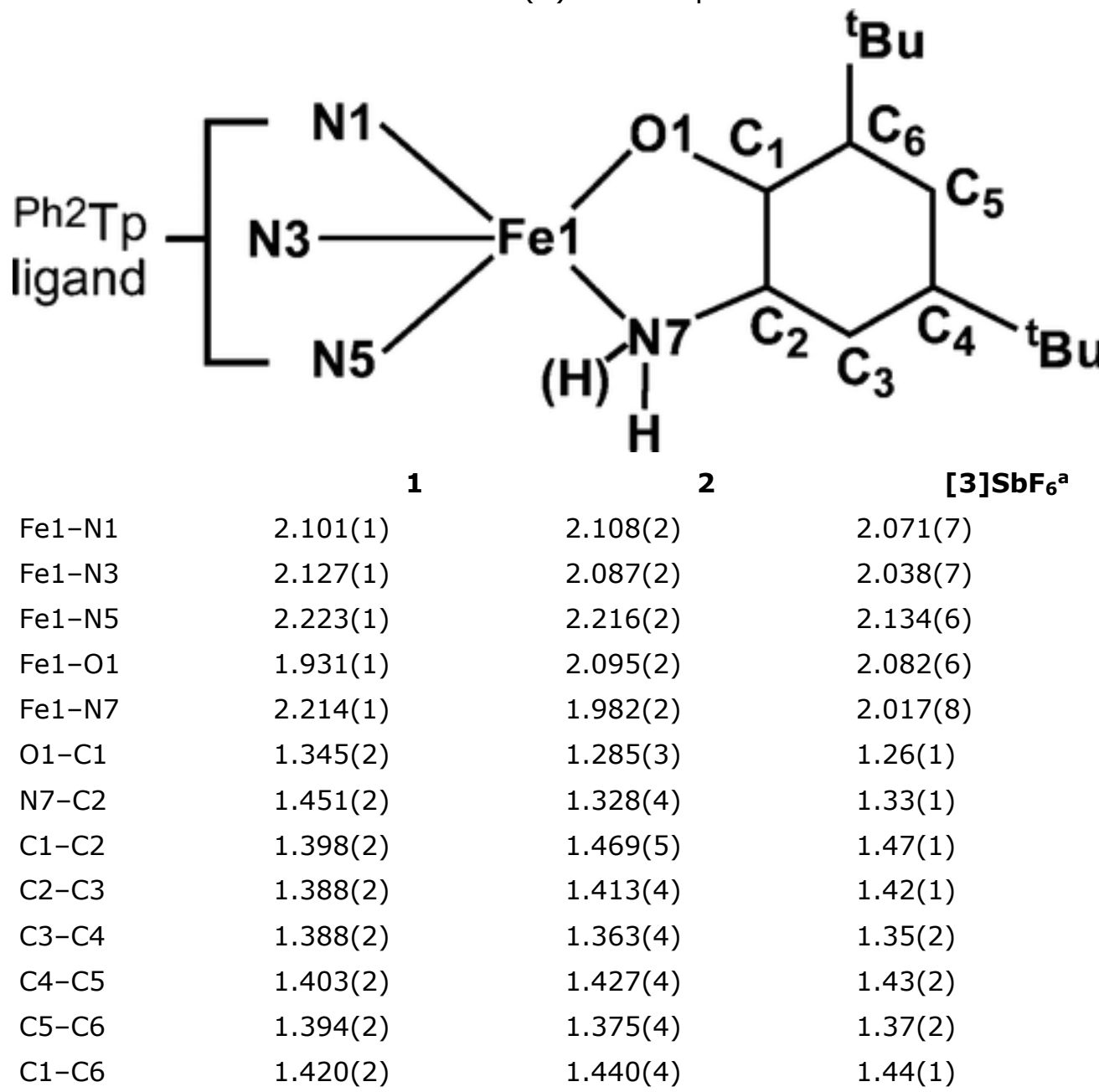

aThe bond distances listed here represent the average distance in the two independent units of $[\mathbf{3}]^{+}$, while the uncertainty is taken to be the larger of the two $\sigma$-values.

Further evidence in favor of a ligand-based radical was obtained from density functional theory (DFT) calculations. Two geometryoptimized models of $\mathbf{2}$ with $S=3 / 2$ were computed that differ with respect to their electronic configurations. Analysis of the geometric and electronic structure of the first model $\left(\mathbf{2}_{\mathbf{A}}\right)$ indicates that it contains an intermediate-spin $\mathrm{Fe}^{3+}$ center coordinated to a closed-shell imidophenolate ligand, ${ }^{t B u} A P^{2-}$. The optimized structure of $\mathbf{2}_{\mathbf{A}}$ features a square-pyramidal geometry $(T=0.18)$ with very short $\mathrm{Fe}-\mathrm{O} 1$ and Fe- 
N7 distances of $\sim 1.87 \AA$, in poor agreement with the experimental structure (Table S2). Furthermore, the computed bond distances for the ${ }^{t B u} A P^{2-}$ ligand deviate sharply from the distances found experimentally for $\mathbf{2}$, with nearly all such differences being significantly greater than the estimated error $(3 \sigma)$ in the crystallographic data. The second model ( $\mathbf{2}_{\mathbf{B}}$ ) was generated via a broken-symmetry calculation in order to obtain the $\left[\left({ }^{\mathrm{Ph} 2} \mathrm{Tp}\right) \mathrm{Fe}^{2+}\left({ }^{t \mathrm{Bu}} \mathrm{ISQ}\right)\right]$ electronic configuration described above. The resulting structure accurately reproduces the overall trigonal-bipyramidal geometry of $\mathbf{2}$ and provides reasonably consistent Fe-ligand distances. Most importantly, the computed and experimental ${ }^{t B u}{ } S_{S Q}{ }^{-}$bond distances exhibit remarkable agreement, with an rms deviation of merely $0.007 \AA$ (Table S2). Model $\mathbf{2}_{\mathbf{B}}$ is also 9 $\mathrm{kcal} / \mathrm{mol}$ more stable than $\mathbf{2}_{\mathbf{A}}$, indicating an energetic preference for the $\mathrm{Fe}^{2+}{ }^{t \mathrm{Bu}} \mathrm{ISQ}$ form.

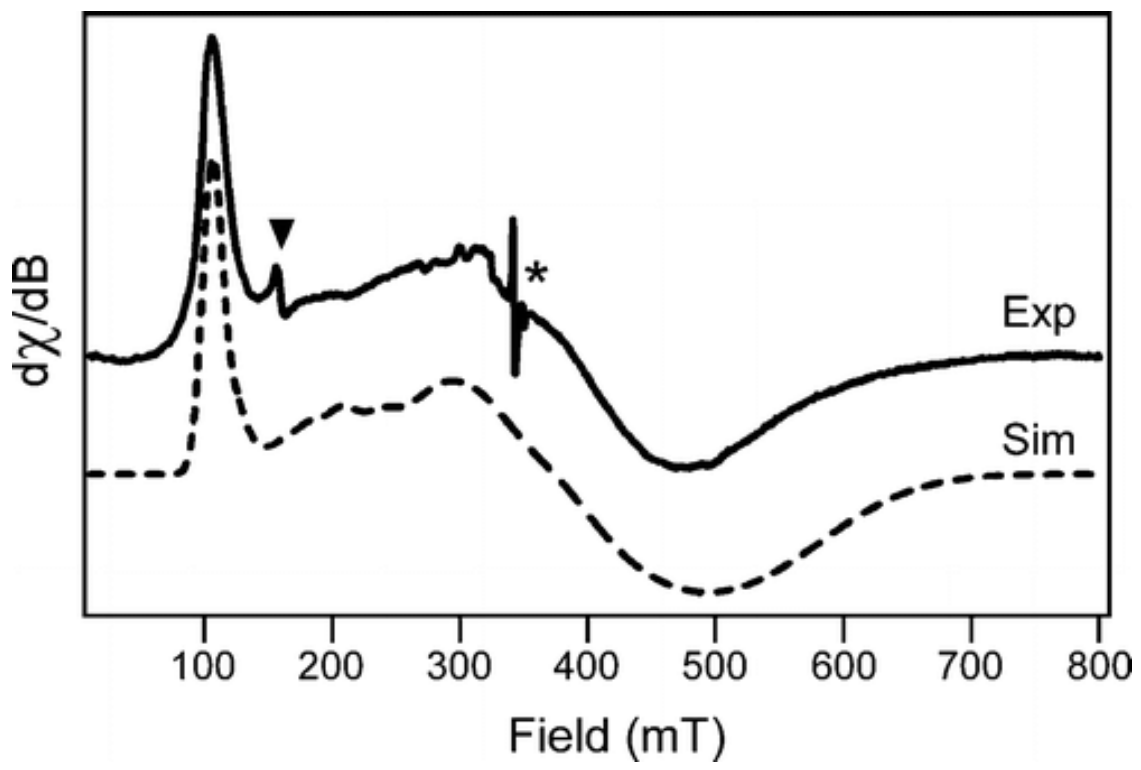

Figure 3. X-band EPR spectrum of $\mathbf{2}$ at $20 \mathrm{~K}$. The derivative-shaped feature at $g=$ $4.3(\nabla)$ arises from a minor ferric impurity, while the feature at $g=2.0(*)$ is due to a residual TTBP radical. Parameters used to generate the simulated spectrum are provided in the text.

To the best of our knowledge, the electronic structure of $\mathbf{2}$ has no precedent among synthetic complexes. While $\mathrm{Fe}^{2+}-\mathrm{SQ}$ intermediates are often invoked in the mechanisms of catechol dioxygenases, all relevant models to date feature unambiguous $\left[\mathrm{Fe}^{3+}-\right.$ catecholate $]^{+}$units. ${ }^{17,18}$ Similarly, the $\mathrm{Fe}^{3+}$-ISQ complexes generated by Wieghardt and co-workers exclusively undergo ligand-based reductions to give the corresponding $\mathrm{Fe}^{3+}-\mathrm{AP}$ species. ${ }^{8,9}$ The unique 
$\mathrm{Fe}^{2+}-\mathrm{ISQ}$ configuration of $\mathbf{2}$ is likely due to the presence of a highspin, 5C Fe ion, whereas related complexes prepared by Wieghardt (such as $\left[(\mathrm{L}) \mathrm{Fe}^{3+}\left({ }^{\mathrm{R}} \mathrm{ISQ}\right)\right]^{+}$, where $\mathrm{L}=$ cis-cyclam and $\mathrm{R}=\mathrm{H}$ or ${ }^{t} \mathrm{Bu}$ ) generally feature low-spin, 6C Fe centers. ${ }^{8}$ Thus, changes in spin state and coordination geometry are capable of shifting the delicate balance between the $\mathrm{Fe}^{2+}-\mathrm{ISQ}$ and $\mathrm{Fe}^{3+}-\mathrm{AP}$ valence tautomers.

Reaction of $\mathbf{2}$ with 1 equiv of an acetylferrocenium salt in $\mathrm{CH}_{2} \mathrm{Cl}_{2}$ provides a dark green species, $[3]^{+}$, with intense absorption features at 770 and $430 \mathrm{~nm}$ (Figure 2). Treatment of [3] ${ }^{+}$with 1 equiv of reductant (such as $\mathrm{Fe}\left(\mathrm{Cp}^{*}\right)_{2}$ ) fully regenerates $\mathbf{2}$ (Figure $\mathrm{S} 2$ ), indicating that the two species are related by a reversible one-electron process. EPR experiments with frozen solutions of $[\mathbf{3}]^{+}$failed to detect a signal in either perpendicular or parallel mode, indicative of an integer-spin system. Indeed, the magnetic moment of $[\mathbf{3}]^{+}$was found to be $5.0(1) \mu_{B}$ at RT, close to the spin-only value for an $S=2$ paramagnet.

X-ray quality crystals of [3] $\mathrm{SbF}_{6}$ were prepared by vapor diffusion of pentane into a concentrated dichloroethane solution. The resulting structure (Figure S3) contains two symmetrically independent Fe units, each featuring a distorted square-pyramidal geometry ( $\mathrm{T}=$ 0.42 and 0.38 ). Despite the difference in charge, complexes [3] ${ }^{+}$and 2 have identical atomic compositions. Yet the average $\mathrm{Fe}-\mathrm{N}_{\mathrm{Tp}}$ bond distance shortens from 2.132 to $2.081 \AA$ upon conversion of $\mathbf{2}$ to [3] ${ }^{+}$, suggesting an increase in Fe-based charge. While the structural parameters of the bidentate $\mathrm{O}, \mathrm{N}$-donor ligand of [3] ${ }^{+}$are consistent with a ${ }^{t B u}{ }^{B S Q} Q^{-}$radical, it was not possible to rule out a neutral iminobenzoquinonate ligand ( $\left.{ }^{\mathrm{Bu}} \mathrm{IBQ}\right)$ due to sizable uncertainties in the bond distances.

We therefore turned to DFT calculations to further explore the electronic structure of [3] ${ }^{+}$. The resulting geometry-optimized model, $\left[3_{\mathrm{DFT}}\right]^{+}$, exhibits good agreement with the crystallographic data, although the DFT structure is more distorted toward the trigonalbipyramidal limit ( $\mathrm{T}=0.64$; Table S3). The computed Fe-ligand bond distances nicely match the experimental values ( $r$ s deviation $=0.022$ $\AA$ ), indicating that the calculation converges to the correct $S=2$ electronic configuration. Comparison of [ $\left.\mathbf{3}_{\mathrm{DFT}}\right]^{+}$and $\mathbf{2}_{\mathbf{B}}$ reveals more pronounced "quinoid" character in the $\mathrm{O}, \mathrm{N}$-donor ligand of the former. 
Using the experimentally derived correlations of bond distances and ligand oxidation states recently published by Brown, the $\mathrm{O}, \mathrm{N}$-donor ligand of $\left[3_{\mathrm{DFT}}\right]^{+}$has an oxidation state of $-0.35(5)$ (i.e., partway between ISQ ${ }^{1-}$ and $\left.\mathrm{IBQ}^{0}\right) .{ }^{19}$ Moreoever, the highest-occupied spindown $\mathrm{MO}(\beta-\mathrm{HOMO})$ of $[3]^{+}$contains roughly equal $\mathrm{Fe}$ and ligand character ( 47 and $42 \%$, respectively), and the $\beta$-LUMO is evenly delocalized over the two units (Figure S4). Thus, the DFT results suggest that the electronic structure of [3] ${ }^{+}$lies between the $\mathrm{Fe}^{3+}$ ${ }^{t B u} I S Q$ and $\mathrm{Fe}^{2+}{ }^{t \mathrm{Bu}} \mathrm{IBQ}$ limits. Detailed spectroscopic studies are currently underway to better understand the electronic structure of $[3]^{+}$.

Complexes 1-3 replicate key structural and electronic aspects of the proposed $o$-aminophenol dioxygenase mechanism. In particular, the conversion of $\mathbf{1} \rightarrow \mathbf{2}$ mimics the transformation of the enzymesubstrate complex (A) into a ferrous-ISQ species (B) via coupled proton and electron transfers. Our results therefore provide a synthetic precedent for the existence of $\mathrm{Fe}^{2+}-\mathrm{ISQ}$ intermediates in enzymatic catalysis. Of course, complex $\mathbf{2}$ is an imperfect model of intermediate B, since it lacks the coordinated superoxo ligand. Attempts are currently in progress to characterize species formed during the reaction of $\mathbf{1}$ and $\mathbf{2}$ with $\mathrm{O}_{2}$ (and its surrogate, NO). These studies will yield further insights into the role of noninnocent ligands in ringcleaving dioxygenase mechanisms.

\section{Supporting Information}

Experimental details, computational methods and models, crystallographic structures and data (CIFs), and absorption spectra of the interconversion of $\mathbf{2}$ and $[\mathbf{3}]^{+}$. This material is available free of charge via the Internet at http://pubs.acs.org.

The authors declare no competing financial interest.

\section{Acknowledgment}

We thank Dr. Brian Bennett for generously allowing us to perform EPR experiments at the National Biomedical EPR Center (supported by NIH P41 Grant EB001980), and for assistance with the simulation. We are also grateful to the NSF (CAREER CHE-1056845) and Marquette University for financial support. Society and permission has been granted for this version to appear in e-Publications@Marquette. American Chemical Society does not grant permission for this article to be further copied/distributed or hosted elsewhere without the express permission from American Chemical Society. 
NOT THE PUBLISHED VERSION; this is the author's final, peer-reviewed manuscript. The published version may be accessed by following the link in the citation at the bottom of the page.

\section{References}

${ }^{1}$ (a) Costas, M.; Mehn, M. P.; Jensen, M. P.; Que, L., Jr. Chem. Rev. 2004, 104, 939- 986. (b) Vaillancourt, F. H.; Bolin, J. T.; Eltis, L. D. Crit. Rev. Biochem. Mol. 2006, 41, 241- 267. (c) Lipscomb, J. D. Curr. Opin. Struct. Biol. 2008, 18, 644- 649

2(a) Li, X. W.; Guo, M.; Fan, J.; Tang, W. Y.; Wang, D. Q.; Ge, H. H.; Rong, H.; Teng, M. K.; Niu, L. W.; Liu, Q.; Hao, Q. Protein Sci. 2006, 15, 761- 773. (b) Zhang, Y.; Colabroy, K. L.; Begley, T. P.; Ealick, S. E. Biochemistry 2005, 44, 7632- 7643

3(a) Bassan, A.; Borowski, T.; Siegbahn, P. E. M. Dalton Trans. 2004, 31533162. (b) Siegbahn, P. E. M.; Haeffner, F. J. Am. Chem. Soc. 2004, $126,8919-8932$

${ }^{4}$ Deeth, R. J.; Bugg, T. D. H. J. Biol. Inorg. Chem. 2003, 8, 409- 418

${ }^{5}$ Spence, E. L.; Langley, G. J.; Bugg, T. D. H. J. Am. Chem. Soc. 1996, 118, 8336- 8343

${ }^{6}$ Kovaleva, E. G.; Lipscomb, J. D. Science 2007, 316, 453- 457

${ }^{7}$ Poddel'sky, A. I.; Cherkasov, V. K.; Abakumov, G. A. Coord. Chem. Rev. 2009, 253, 291- 324

${ }^{8}$ Chun, H.; Bill, E.; Bothe, E.; Weyhermuller, T.; Wieghardt, K. Inorg. Chem. 2002, 41, 5091- 5099

${ }^{9}$ (a) Min, K. S.; Weyhermuller, T.; Wieghardt, K. Dalton Trans. 2003, 11261132. (b) Min, K. S.; Weyhermuller, T.; Wieghardt, K. Dalton Trans. 2004, 178- 186

${ }^{10}$ For other examples of $\mathrm{Fe}^{3+}-$ ISQ complexes, see: (a) Mukherjee, S.; Weyhermuller, T.; Bill, E.; Wieghardt, K.; Chaudhuri, P. Inorg. Chem. 2005, 44, 7099- 7108. (b) Chun, H. P.; Bill, E.; Weyhermuller, T.; Wieghardt, K. Inorg. Chem. 2003, 42, 5612- 5620. (c) Chun, H.; Verani, C. N.; Chaudhuri, P.; Bothe, E.; Bill, E.; Weyhermuller, T.; Wieghardt, K. Inorg. Chem. 2001, 40, 4157-4166. (d) Chun, H.; Weyhermuller, T.; Bill, E.; Wieghardt, K. Angew. Chem., Int. Ed. 2001, 40, 2489- 2492

${ }^{11}$ For examples of $\mathrm{Fe}^{3+}-\mathrm{SQ}$ complexes, see: (a) Attia, A. S.; Conklin, B. J.; Lange, C. W.; Pierpont, C. G. Inorg. Chem. 1996, 35, 1033- 1038. (b) Koch, W. O.; Schunemann, V.; Gerdan, M.; Trautwein, A. X.; Kruger, H. J. Chem.-Eur. J. 1998, 4, 1255- 1265. (c) Pierpont, C. G. Coord. Chem. Rev. 2001, 219, 415- 433

${ }^{12}$ Abbreviations: ${ }^{\mathrm{Ph}} 2 \mathrm{Tp}=$ hydrotris(3,5-diphenylpyrazol-1-yl)borate $(1-) \cdot{ }^{\mathrm{R}} \mathrm{AP}=$ 0 -imidophenolate(2-) anion with R-groups at the 4- and 6-positions. ${ }^{R} \mathrm{ISQ}=0$-iminobenzosemiquinone(1-) with R-groups at the 4- and 6positions.

${ }^{13}$ Mehn, M. P.; Fujisawa, K.; Hegg, E. L.; Que, L., Jr. J. Am. Chem. Soc. 2003, $125,7828-7842$ 
NOT THE PUBLISHED VERSION; this is the author's final, peer-reviewed manuscript. The published version may be accessed by following the link in the citation at the bottom of the page.

${ }^{14}$ Park, H.; Baus, J. S.; Lindeman, S. V.; Fiedler, A. T. Inorg. Chem. 2011, 50, $11978-11989$

${ }^{15}$ The $\mathrm{T}$-value is 0.0 in idealized square-planar geometries and 1.0 in idealized trigonal-bipyramidal geometries. See: Addison, A. W.; Rao, T. N.; Reedijk, J.; Vanrijn, J.; Verschoor, G. C. J. Chem. Soc., Dalton Trans. $1984,1349-1356$

${ }^{16}$ Bennett, B. In Metals in Biology: Applications of High-resolution EPR to Metalloenzymes; Hanson, G.; Berliner, L., Eds.; Springer: New York, 2010; Vol. 29, pp 345- 370.

${ }^{17}$ (a) Jang, H. G.; Cox, D. D.; Que, L., Jr. J. Am. Chem. Soc. 1991, 113, 9200- 9204. (b) Cox, D. D.; Que, L., Jr. J. Am. Chem. Soc. 1988, 110, 8085- 8092. (c) Bruijnincx, P. C. A.; Lutz, M.; Spek, A. L.; Hagen, W. R.; Weckhuysen, B. M.; vanKoten, G.; Gebbink, R. J. M. K. J. Am. Chem. Soc. 2007, 129, 2275- 2286

${ }^{18}$ The low-energy catecholate $\rightarrow \mathrm{Fe}^{3+}$ charge transfer transitions $(700-900 \mathrm{~nm}$ ) exhibited by some models point to a low-lying excited state with $\mathrm{Fe}^{2+}-$ SQ character. Interaction with this excited state may introduce a small amount of SQ character into the ground state.

${ }^{19}$ Brown, S. N. Inorg. Chem. 2012, 51, 1251- 1260. A least-squares fitting of the $\mathrm{O}, \mathrm{N}$-ligand bond distances was used to obtain the apparent ligand oxidation state. 